\title{
Efficacy of Korean Red Ginseng Supplementation on Eradication Rate and Gastric Volatile Sulfur Compound Levels after Helicobacter pylori Eradication Therapy
}

\author{
So Jung Lee ${ }^{1}$, Ji Young Park ${ }^{1}$, Ki Seok Choi ${ }^{2}$, Chan Young Ock², Kyung Sook Hong ${ }^{2}$, Yoon Jae Kim ${ }^{1}$, \\ Jun Won Chung ${ }^{1}$, and Ki-Baik Hahm ${ }^{1,2^{*}}$ \\ ${ }^{1}$ Department of Gastroenterology, Gachon Graduate School of Medicine Gil Medical Center, Incheon 405-760, Korea \\ ${ }^{2}$ Laboratory of Translational Medicine, Gachon University Lee Gil Ya Cancer and Diabetes Institute, Incheon 406-840, Korea
}

This clinical study was performed to evaluate whether supplementation of proton pump inhibitor (PPI)-based triple therapy with Korean red ginseng can enhance Helicobacter pylori (H. pylori) eradication and reduce levels of halitosis-associated volatile sulfur compounds (VSCs) in the stomach. Seventy-six patients were randomized into an eradication regimen-only group $(n=45)$ or an eradication regimen plus 10 weeks of Korean red ginseng supplementation group ( $n=31)$. The eradication regimen consisted of PPI b.i.d., clarithromycin $500 \mathrm{mg}$ b.i.d., and amoxicillin $1 \mathrm{~g}$ b.i.d.. for seven days. Korean red ginseng supplementation commenced on the last day of the eradication regimen. ${ }^{13} \mathrm{C}$-urea breath test and halimeter measurements were performed prior to protocol repetition. By intention-to-treat analysis, the $H$. pylori eradication rate in the Korean red ginseng group $(77.4 \%, 24$ of 31) was higher than that in the control group $(45.0 \%, 26$ of 45). However, by per protocol analysis, the eradication rate in the Korean red ginseng group was significantly higher than that in the control group (92.3\%, $24 / 26$ vs. $69.4 \%, 26 / 38 ; p<0.05)$. H. pylori infection was significantly associated with increased VSC levels. However, VSC levels decreased significantly in the Korean red ginseng group $(p<0.05)$. In conclusion, supplementation of triple therapy with Korean red ginseng increased the $H$. pylori eradication rate and led to significant reductions in VSC levels, suggesting the usefulness of this substance in combating $H$. pylori infection.

Keywords: Helicobacter pylori, Korean red ginseng, Eradication, Halimeter, Supplementation, Chronic atrophic gastritis

\section{INTRODUCTION}

Helicobacter pylori (H. pylori) infection is found in $70 \%$ to $90 \%$ of the population in developing countries and in $25 \%$ to $50 \%$ in developed countries, and thus poses significant public health risks [1]. H. pylori are known to play a major role in the pathogenesis of chronic and atrophic gastritis, gastric and duodenal ulcers, and gastric malignancies, including adenocarcinoma and mucosa-associated lymphoma tissue lympho- ma [2,3]. Consequently, a great deal of emphasis has been placed on its eradication, as this would reduce the prevalence of a variety of conditions, possibly including gastric carcinomas $[4,5]$. According to the Maastricht consensus, the first-line therapy for $H$. pylori eradication is a combination of a proton pump inhibitor (PPI) or ranitidine bismuth citrate and clarithromycin plus either amoxicillin or metronidazole [6,7]. With these first- (c) This is an Open Access article distributed under the terms of the Cre-
ative Commons Attribution Non-Commercial License (http://creativecom-
mons.org/licenses/by-nc/3.0/) which permits unrestricted non-commercial
use, distribution, and reproduction in any medium, provided the original
work is properly cited.
Received 16 Feb. 2010, Revised 16 Apr. 2010, Accepted 19 Apr. 2010

*Corresponding author

E-mail: hahmkb@gachon.ac.kr

Tel: +82-32-899-6055, Fax: +82-32-899-6054 
line therapies the eradication rate ranges from $75 \%$ to $98 \%$ with the median at circa $80 \%$. Therefore, around $20 \%$ of patients are expected to be unresponsive to treatment, a proportion that may be higher in locations with a high prevalence of resistant $H$. pylori strains, such as Korea and Japan [8]. The recommended secondline therapy is a quadruple regimen composed of tetracycline, metronidazole, bismuth salt, and a PPI. However, the efficacy of these regimens is limited by poor compliance, treatment duration, number and dose of prescribed drugs, and bacterial resistance to antibiotics [9].

Although bacterial resistance and poor patient compliance are believed to be the primary factors, the exact reasons for treatment failure remain unclear. Occurrence of mild but unpleasant side effects such as diarrhea, nausea, vomiting, and abdominal bloating and pain may cause the patient to interrupt the regimen, thus leading to increased bacterial resistance [10]. Therefore, gastroenterologists and microbiologists continue to search for new therapies due to the increasing prevalence of H. pylori infection and the physiological and pharmacoeconomic burden of the second-line therapy. To increase eradication rates of first-line therapy, several clinical trials involving extending treatment duration to more than one week, use of higher doses of per protocol (PP), and/or new antibiotics such as quinolones, use of quadruple therapy, or addition of probiotics, vitamin $\mathrm{C}$, bovine lactoferrin, ginseng, wine, garlic, honey, and cranberry have been carried out [11-15].

Previous studies have suggested that Korean red ginseng 1) inhibits $H$. pylori colonization, 2) exhibits antioxidative and antiinflammatory effects during $H$. pylori infection, 3) provides efficient restorative action, 4) inhibits expression of genes associated with generation of volatile sulfur compounds (VSCs), and 5) increases eradication rates in addition to attenuating $H$. pyloriassociated halitosis [16-19]. Here, we investigated the effects of supplementation of triple therapy with Korean red ginseng on both $H$. pylori eradication rates and $H$. pylori-associated halitosis.

\section{MATERIALS AND METHODS}

\section{Patient recruitment}

Individuals with dyspepsia and indigestion (76 total; 35 male, 41 female), with a mean age of $51.6 \pm 14.5$ years (range, 41 to 70 years), were recruited into the study after providing informed consent. All subjects showed chronic atrophic gastritis on the antrum or corpus. Urea breath test (UBT), rapid urease test, and
Warthin silver staining of biopsied gastric mucosa were performed to characterize patients as $\mathrm{H}$. pylori-associated chronic atrophic gastritis-positive or negative. Halitosis, a fetid breath odor, was objectively documented by halimeter test; a reading of $>100 \mathrm{ppb}$ was taken as halitosis-positive [20-22]. Individuals taking antibiotics, proton pump inhibitors, $\mathrm{H}_{2}$ receptor antagonists, nonsteroidal anti-inflammatory drugs, or antihistaminic drugs, were excluded from the study. Furthermore, based on data from the General Health Check Program (Gil Medical Center, Incheon), which included a dental check, blood tests including peripheral blood test, systemic biochemical tests including renal, hepatic, and lipid tests, a serological test for hepatitis, tests for cancer biomarkers, and GI endoscopy including gastroscopy and colonoscopy), individuals with fundamental systemic illnesses, including diabetes, tuberculosis, renal insufficiency, liver disease, etc., or dental problems, were excluded from the study. The study protocol was approved by the institutional review board of Gachon University Gil Medical Center (Institutional Review Board [IRB], March 2009). Subjects (76 total) were randomized into an eradication regimen-only group (eradication alone group, $n=45$ ) or eradication regimen plus 10 weeks of Korean red ginseng-supplemented group (eradication plus Korean red ginseng group, $n=31$ ). Korean red ginseng was administered in capsules ( $300 \mathrm{mg} /$ capsule) provided by the Korea Ginseng Corporation (Jeongkwanjang red ginseng powder; Daejeon, Korea). A total of $2.7 \mathrm{~g}$ of Korean red ginseng capsules were given per day, each dose consisting of three capsules, t.i.d., for 10 weeks following cessation of the eradication regimen. The eradication regimen consisted of pantoprazole (40 mg b.i.d.; Amore-Pacific Pharma, Seoul, Korea), clarithromycin (500 mg b.i.d.; Korea Pharma, Icheon, Korea), and amoxicillin ( $1 \mathrm{~g}$ b.i.d.; Chongkeundang Pharma, Seoul, Korea) for seven days. Korean red ginseng (900 mg t.i.d.) supplementation commenced on the last day of triple therapy. ${ }^{13} \mathrm{C}$-urea breath tests and halimeter measurements were performed both immediately before and 12 weeks after commencement of treatment.

\section{Urea breath test}

UBT was performed both immediately before and after cessation of treatment (10 weeks after eradication regimen and at least one week after cessation of Korean red ginseng). ${ }^{13} \mathrm{C}$-labeled urea $(100 \mathrm{mg})$ was produced by Otsuka Pharmaceutical Co (Tokushima, Japan). UBT was defined as positive when $\Delta \Delta^{13} \mathrm{CO}_{2}$ was above 2.5 (nil\%) at 20 minutes after ingestion of ${ }^{13} \mathrm{C}$-urea. 


\section{Measurement of VSCs}

The halimeter (Model RH-17K; Interscan Co., Chatsworth, CA, USA) was adjusted to zero in ambient air prior to obtaining measurements. Subjects were asked to breathe through the nose, with the mouth closed, for one minute. A straw attached to the halimeter was then inserted into the mouth and air was withdrawn for analysis. Concentrations were determined in triplicate and the mean values were calculated. Therefore, the data reflected the mean level of VSCs originating from the gastric lumen or stomal area. As individuals with poor oral hygiene or those with dental caries were excluded, mean VSC levels and subjective visual analogue scaled levels of halitosis represented were recorded as "levels of halitosis." VSC levels in the breath were recorded as ppb of sulfide equivalents. Concentrations were determined in triplicate and the mean values were calculated. Measurement of VSCs was usually performed in the morning under fasting conditions to avoid the influence of ingested foods.

\section{Gas chromatography for VSC concentrations in gas- tric juice}

Separation and calibration of VSCs were performed by gas chromatography (GC; Agilent $6890 \mathrm{~N}$, Agilent Technologies, Wilmington, DE, USA) using a flame photometric detector specific for sulfur compounds. We found that $60^{\circ} \mathrm{C}$ was the ideal temperature for evaporating gastric juices for GC analysis. Peak areas and retention times were recorded using ChemStation software (3365 ChemStation revision A09; Agilent Technologies). Gastric juice was heated at $60^{\circ} \mathrm{C}$ to evaporate gas, $500 \mathrm{~mL}$ of which was entrapped in a syringe for gas chromatography/flame photometric detection (FPD) analysis. Gastric juices $(5 \mathrm{~mL})$ were aspirated during endoscopy using an aspiration tube inserted into the biopsy channel (Olympus, Tokyo, Japan) and stored at $-70^{\circ} \mathrm{C}$ until required. To our knowledge, this is the first report of the measurement of VSC levels in aspirated gastric juice. This was made possible by the development of the FPD-based protocol [9].

\section{Statistical analysis}

For intention-to-treat (ITT) analysis, all patients enrolled in the study were included. However, for PP analysis, those who dropped out due to either taking less than $80 \%$ of any of the prescribed drugs or adverse events did not undergo final ${ }^{13} \mathrm{C}$-UBT or halimeter breath tests. Eradication rates were compared by $\chi^{2}$ test. These data were compared with those obtained from the $t$-test and $p<0.05$ was considered significant.

\section{RESULTS}

\section{Patient population}

A total of 76 patients were enrolled from the GI endoscopy center and out-patient department of Gachon University Gil Medical Center after IRB approval. Of these, 45 were included in the eradication alone group and 31 were included in the eradication plus Korean red ginseng group, assigned randomly based on patient registration number. All of these patients showed H. pyloriassociated chronic atrophic gastritis (CAG). Baseline characteristics were similar in the two groups: mean age, male: female ratio, proportion of smokers and alcohol drinkers and CAG in the corpus or antrum. Of the 45 subjects in the eradication-only group, seven were excluded from PP analysis due to discontinued therapy (four subjects), lack of follow-up (two subjects), and non-compliance in one subject, who adhered to the study protocol for only three days. Of the 31 subjects in the eradication plus Korean red ginseng group, five were excluded from PP analysis due to lack of followup (four subjects) and discontinuation of therapy by one subject, who stopped taking Korean red ginseng due to dyspeptic symptoms. The loss of follow-up in four subjects in the Korean red ginseng group may have been attributable to a change in clinical trial nurse (Fig. 1).

\section{H. pylori eradication rates}

According to ITT analysis, eradication rates were $77.4 \%$ (24 of 31 ) in the Korean red ginseng group, compared to $51.0 \%$ (26 of 45 ) in the eradication-only group; this difference was not significant. However, PP analysis suggested that successful eradication of $H$. pylori was achieved in 24 of 26 patients $(92.3 \%)$ in the Korean red ginseng group, which was significantly higher than that in the eradication-only group (26 of 38, 69.4\%; $p<0.05$ ) (Fig. 2a). No subjects in the Korean red ginseng group were non-compliant, whereas one subject in the eradication-only group adhered to the protocol for only three days. One subject stopped taking Korean red ginseng supplementation due to epigastric pain and bloating, whereas four subjects in the eradication-only group discontinued medication due to diarrhea $(n=2)$, dizziness and nausea in $(n=1)$ and bitterness and epigastric soreness $(n=1)$. Four subjects in the Korean red ginseng group and one in the eradication-only group were lost to follow-up; we speculated that this was due to a change in medical staff (the clinical trial nurse) after the 


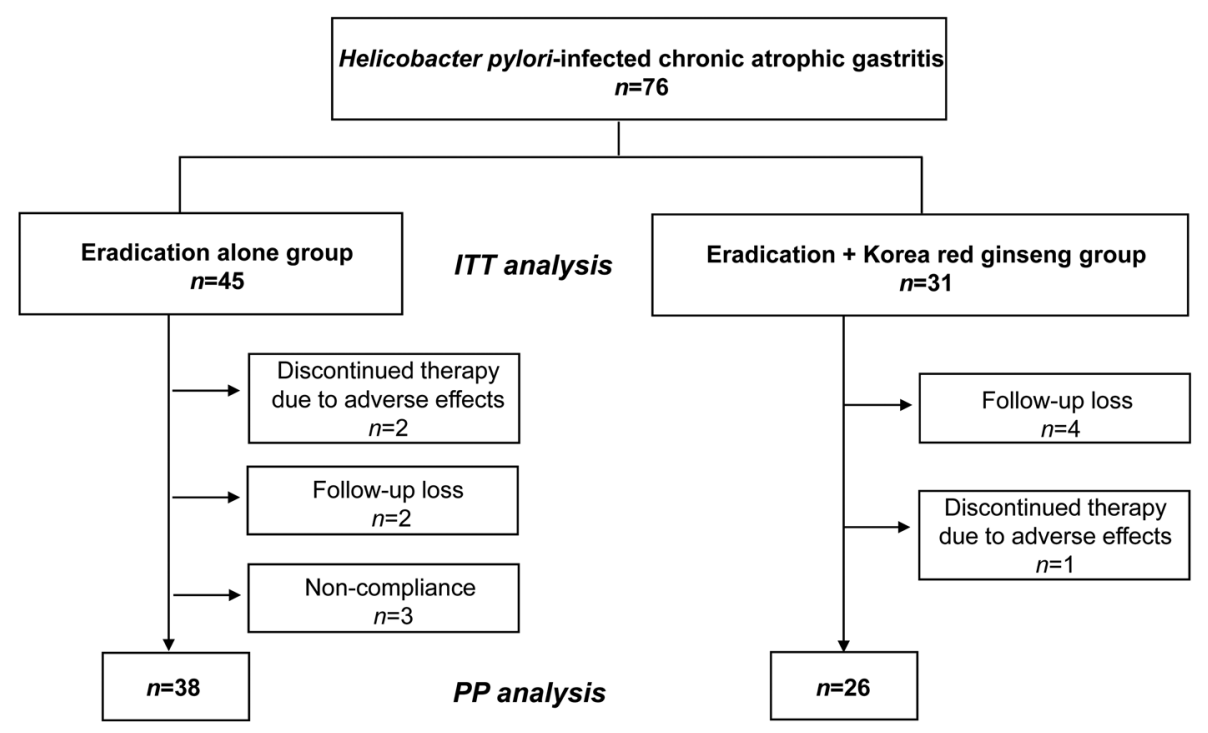

Fig. 1. Flow diagram of the study, including intention-to-treat (ITT) and per protocol (PP) analyses.

trial had begun.

As we have previously reported eradication rates $[18,19]$ (albeit at differing time points than the data presented here), these data (Fig. 2a upper and middle panels) are presented together with those of the study described here (Fig. 2a lower panel). Although the eradication plus Korean red ginseng regime resulted in higher eradication rates than the eradication-only regime in each trial, statistical significance was not achieved, most likely due to the small number of subjects in each trial. However, when these data were combined (Fig. 2b), supplementation with 10 weeks of Korean red ginseng (Jeongkwanjang red ginseng capsule, $2.7 \mathrm{~g}$ /day; Korea Ginseng Cooperation) significantly augmented eradication rates (eradication-only group $75 / 102,73.5 \%$ vs. eradication plus Korean red ginseng group 82/90, 91.1\%; $p<0.005$ ).

\section{H. pylori infection and VSC levels}

Data from a previous study [23] suggested that breath VSC levels indicated the presence of erosive or mucosal injury in patients with functional dyspepsia. Thus, to determine the effects of $H$. pylori infection on VSC levels, we recruited 55 subjects with functional dyspepsia. VSC levels were also determined in individuals (110) with mild chronic superficial gastritis (CSG) by endoscopy, and whose H. pylori status had been determined by rapid urease test, UBT, and Warthin silver staining were negative.

A total of 55 subjects ( 21 male and 34 female, mean age $34.3 \pm 10.2$ years; range, 21 to 51 years) were included in the study. VSC levels were significantly different between $H$. pylori-positive CSG patients and those who were $H$. pylori-negative (Fig. 3a). This suggests that $H$. pylori infection is associated with increased VSC levels. Furthermore, data obtained by GC/FPD suggested that $\mathrm{H}_{2} \mathrm{~S}$ was present in the gastric juice of individuals with confirmed H. pylori infection (Fig. 3b).

\section{Attenuation of $\boldsymbol{H}$. pylori-associated halimeter ppb levels with the supplementation of Korean red gin- seng}

Supplementation with Korean red ginseng significantly decreased the mean levels of VSCs as compared to triple therapy alone $(p<0.05$, Fig. $4 a)$. Although the eradication regimen alone decreased the mean levels of halimeter ppb, the difference was not significant. These data suggested that supplementation with Korean red ginseng resulted in health benefits other than enhancement of $H$. pylori eradication. Although there is no clear definition of which VSC levels are diagnostic of halitosis, concentrations lower than $100 \mathrm{ppb}$ are generally acknowledged as denoting no halitosis [21-23]. When we analyzed how many patients were ppb $<100$ according to group, the number of patients in the Korean red ginseng group was higher than that in the eradication alone group in these goals, but the difference was not statistically significant (Fig. 4b). All subjects who received Korean red ginseng supplementation showed a decrease in VSC level of $>30 \%$, compared with only $52.9 \%$ of those who did not ( $p<0.05$, Fig. $4 c$ ). Taken together, these data suggest that supplementation with Korean red ginseng led to a significant reduction in $H$. 

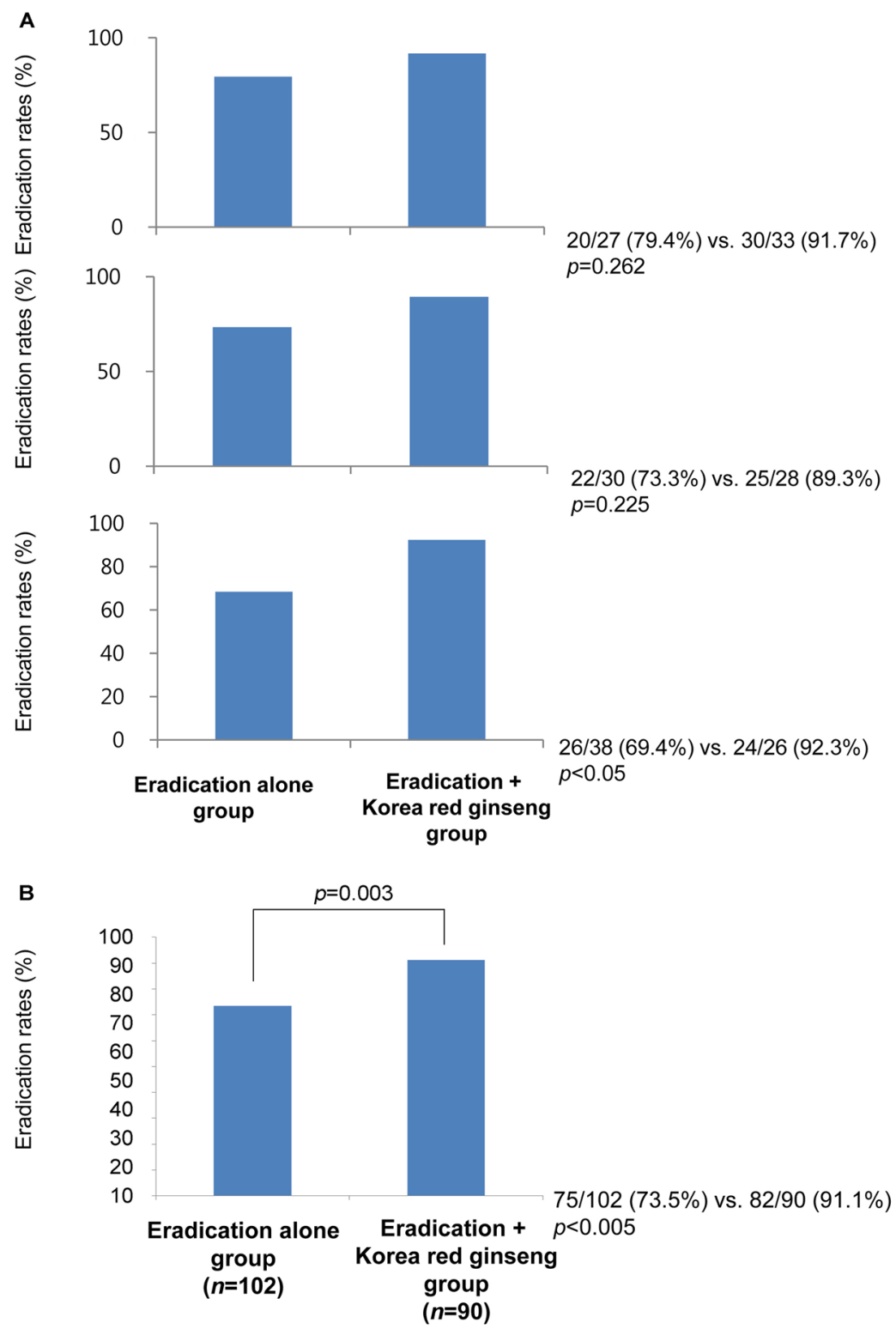

Fig. 2. Eradication rates by patient group: eradication alone and eradication plus Korean red ginseng. (a) Eradication rates in three previous clinical trials. We previously conducted three clinical studies $[18,19]$. The first [18] was composed of 60 subjects (27 received only eradication therapy and 33 received eradication therapy plus 10 weeks of Korean red ginseng), the main objective of which trial was to measure the change of pathological scores according to group; eradication rate was obtained only as involved parameter (upper panel). The second [19] was composed of 58 subjects (30 and 28 received eradication therapy only and eradication therapy plus Korean red ginseng, respectively). The objective of this trial was to document the efficacy of Korean red ginseng on halitosis, but eradication rates were also additionally recorded (middle panel). The lower figure shows the results of the current trial. (b) Cumulative results of eradication rates according to group. When data from these three trials was combined, the eradication rate in the Korean red ginseng group was significantly higher than that in the eradication-only group $(p=0.0003)$.

pylori-associated VSC levels.

\section{DISCUSSION}

Supplementation of triple therapy with Korean red ginseng increased $H$. pylori eradication rates and significantly reduced VSC levels in gastric juice. This is especially significant because $H$. pylori eradication alone has been shown to be insufficient to induce remission of chronic atrophic gastritis or precancerous lesions, or to inhibit gastric carcinogenesis [24-26]. Therefore, we inferred that supplementation of traditional therapies with Korean red ginseng would enhance treatment of H. pylori infection, especially in locations with a high incidence of $H$. pylori-associated gastric malignancy. The prevalence of $H$. pylori infection is believed to 


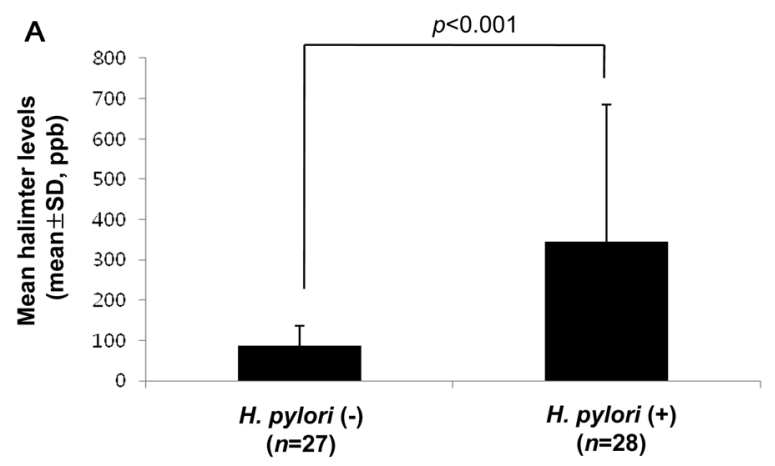

B
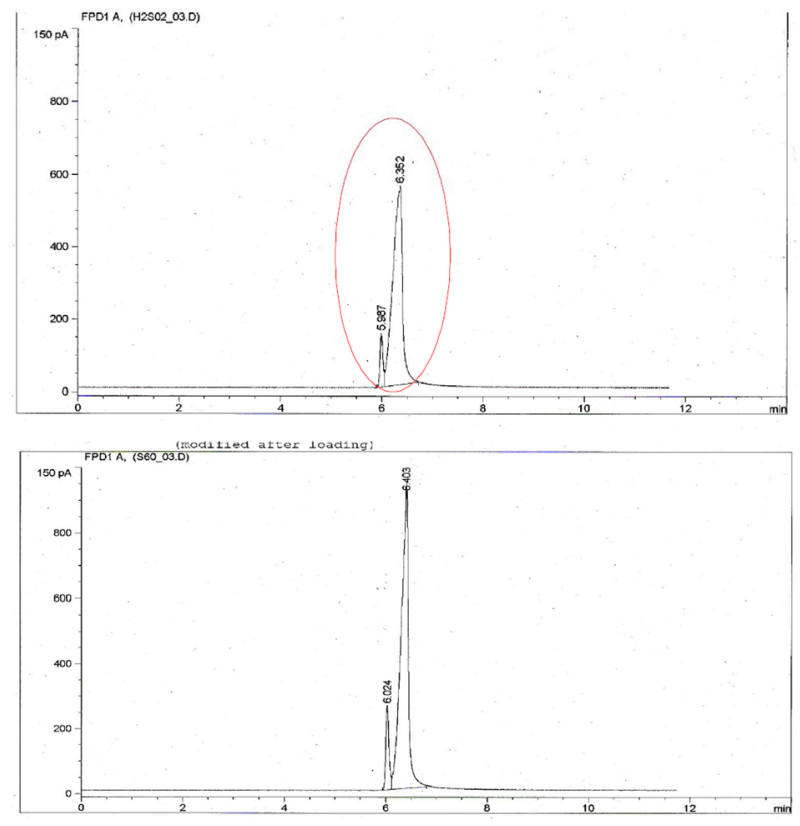

Fig. 3. (a) Mean volatile sulfur compound (VSC) levels in Helicobacter pylori (H. pylori) infected and uninfected subjects. Mean VSC levels of H. pylori (+) patients were significantly greater than those of $H$. pylori (-) patients. (b) Gas chromatographic analysis. Typical chromatograms of headspace air for standard $\mathrm{H}_{2} \mathrm{~S}$ gas (upper) and for gas evaporated from gastric juice (lower). The longitudinal axis represents the response of the flame photometric detector.

decrease as socioeconomic status improves [27]. However, the prevalence rates of $H$. pylori infection and associated gastric cancer remain high in Korea and Japan. Two studies of asymptomatic Korean adults performed in 1998 and 2005 suggested H. pylori prevalence rates of $66.9 \%$ and $59.5 \%$, respectively $[28,29]$. Gastroduodenal symptoms and pathologies develop in $10 \%$ to $15 \%$ of the infected population and $\mathrm{H}$. pylori is recognized as one of the etiological agents of peptic ulcers and a risk factor for the development of gastric adenocarcinoma and lymphoma. Since the World Health Organization classified $H$. pylori as a class 1 carcinogen in 1994, much research on its relationship with gastric cancer has been carried out and many clinical trials have sought to prevent carcinogenesis by eradicating $H$. pylori infection. However, lack of subject compliance and absence of a truly effective anti-H. pylori therapeutic regimen have hindered these efforts.

The ideal regimen for treating $H$. pylori infection remains elusive. Non-antibiotic therapies, including phytomedicinal compounds, probiotics, and antioxidants, have been investigated as potential alternatives or more efficacious options for treatment of $H$. pylori infection [30]. The rationale for these efforts arises from the fact that $H$. pylori antibiotic resistance, particularly to commonly used agents such as clarithromycin and metronidazole, is a major cause of treatment failure. Therefore, appropriate alternatives to antibiotic use must be considered.

Several in vitro and in vivo non-human trials of alternative anti-H. pylori therapies utilizing a variety of substances, including ginseng, wine, garlic, propolis, cranberry, green tea, probiotic, and antioxidants, have been performed. Garlic, capsaicin, cinnamon, probiotics, some Chinese herbal medicines, lactoferrin, and antioxidants (including vitamin C) have been used in human trials, most of which aimed to assess the efficacy of the substances as supplements after cessation of the eradication regimen [31-36]. Some improvements in rates of eradication and side effects were documented. Kim et al. [37] conducted a randomized, open-label study to assess whether PPI-based one-week triple therapy with adjunctive probiotic administration increased $H$. pylori eradication rates and reduced adverse effects. Addition of probiotics to triple therapy did not reduce the side effects of triple therapy, but it increased the eradication rate $(78.7 \%$ eradication therapy alone vs. $87.5 \%$ eradication therapy plus probiotics). Sachdeva and Nagpal [38] performed a meta-analysis to document the effects of fermented milk-based probiotic preparations on H. pylori eradication, and concluded that probiotics improved $H$. pylori eradication rates by approximately $5 \%$ to $15 \%$, whereas the effect on adverse outcomes was unclear. Detailed clinical trials dealing with $H$. $p y$ lori eradication vitamin $\mathrm{C}$ and lactoferrin showed similar results to those of the probiotics studies, leading to the conclusion that supplementation with lactoferrin or vitamin $\mathrm{C}$ or vitamin $\mathrm{E}$ could be effective in increasing H. pylori eradication rates and may be appropriate for patients in whom first-line therapies have failed [38-39]. However, other meta-analyses have not supported the efficacy of supplementary therapy. For example, Chuang et al. [40] and other many investigators [41] have 

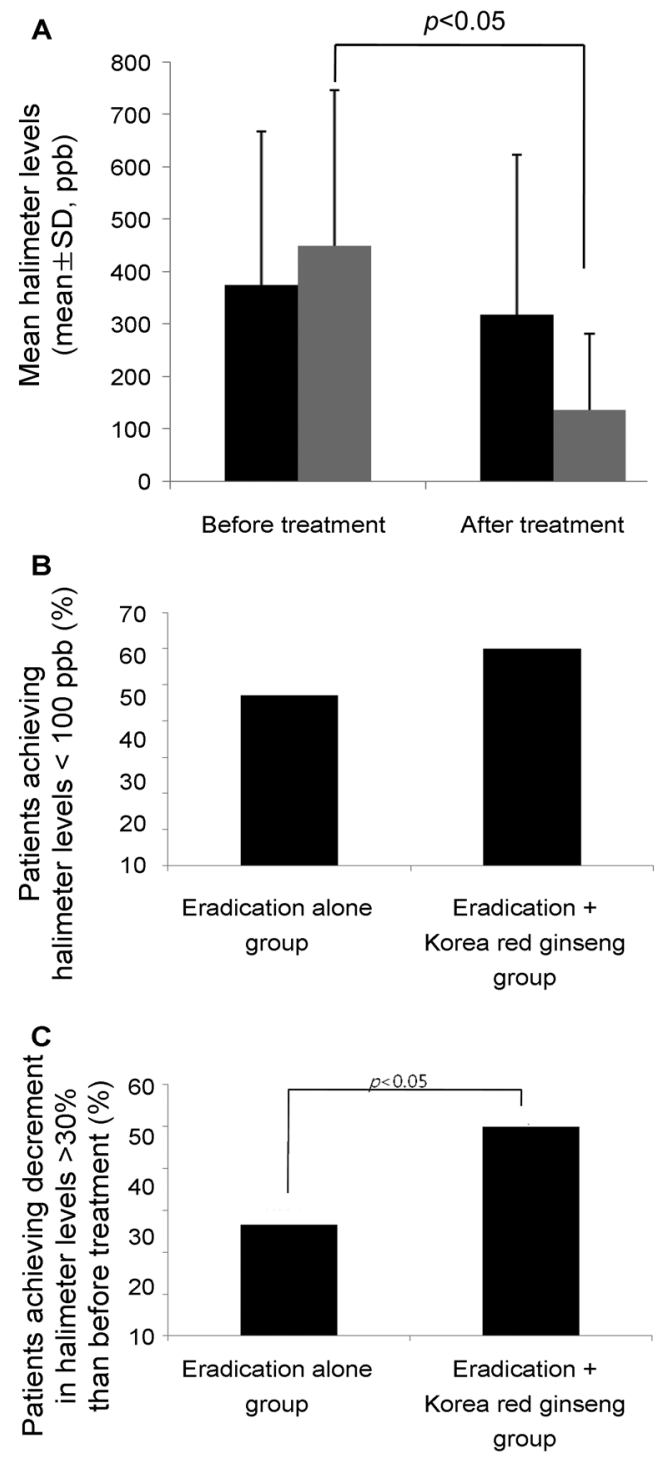

Fig. 4. (a) Comparison of volatile sulfur compound (VSC) levels before and after eradication therapy. Irrespective of group, mean VSC levels were decreased compared to those before treatment. Furthermore, VSC levels were significantly decreased in subjects treated with the eradication regimen plus Korean red ginseng. (b) Proportion of subjects with VSC levels $<100 \mathrm{ppb}$. VSC levels were below $100 \mathrm{ppb}$ in around $60 \%$ of subjects treated with the eradication regimen plus Korean red ginseng, as compared to $47 \%$ of those who received eradication therapy only. These results suggest that eradication of Helicobacter pylori can result in a reduction in halitosis, irrespective of treatment strategy, as reported previously [19]. (c) Proportion of subjects with a decrease in VSC level $>30 \%$ compared to before treatment. All patients in the eradication plus Korean red ginseng group showed a decrease in VSC level $>30 \%$ compared to before treatment.

reported that in patients infected with metronidazolesusceptible $H$. pylori, adding vitamins may even reduce the eradication rate of triple therapy. Regular intake of dietary or dairy products may constitute a low-cost and safe alternative to $H$. pylori treatment, but large-scale or prospective clinical trials are necessary to demonstrate efficacy. The data presented here justify further and larger-scale investigation of the efficacy of Korean red ginseng as a supplement to triple therapy.

A possible link between H. pylori infection and hali- tosis was first reported by Tiomny et al. [42] who followed-up three couples in which either one or both had halitosis. After receiving the eradication regimen, a significant improvement in halitosis was observed. Indeed, halitosis disappeared when $H$. pylori was eradicated. Thereafter, Ierardi et al. [43] reported improvement of halitosis with eradication of $H$. pylori in 19 of 30 subjects, whereas in 11 of 30 , in whom $H$. pylori positivity persisted, halitosis parameters were unchanged. Since these reports, further studies have documented improve- 
ment of halitosis with eradication of $H$. pylori $[44,45]$. Lee et al. [46] first reported production of VSCs by $H$. pylori. The results of the present study added further support to the hypothesis that $H$. pylori infection is associated with increased levels of VSCs in patients with functional dyspepsia. However, as shown in Figs. 4b and $4 \mathrm{c}, H$. pylori infection is not the only cause of halitosis. Thus, Korean red ginseng supplementation may be useful in the treatment of $H$. pylori-associated halitosis [47].

Taken together with previous studies, which suggested that VSC levels were correlated with mucosal inflammation and $H$. pylori infection [23], we concluded that administration of Korean red ginseng after first-line therapy was effective not only in enhancing eradication of $H$. pylori but also in reducing VSC levels in gastric juice.

\section{ACKNOWLEDGEMENTS}

This study was supported by the grant (2009) from the Korean Society of Ginseng funded by Korea Ginseng Corporation.

\section{REFERENCES}

1. Suerbaum S, Michetti P. Helicobacter pylori infection. N Engl J Med 2002;347:1175-1186.

2. Uemura N, Okamoto S, Yamamoto S, Matsumura N, Yamaguchi S, Yamakido M, Taniyama K, Sasaki N, Schlemper RJ. Helicobacter pylori infection and the development of gastric cancer. N Engl J Med 2001;345:784789.

3. Mera R, Fontham ET, Bravo LE, Bravo JC, Piazuelo $\mathrm{MB}$, Camargo MC, Correa P. Long term follow up of patients treated for Helicobacter pylori infection. Gut 2005;54:1536-1540.

4. Wong BC, Lam SK, Wong WM, Chen JS, Zheng TT, Feng RE, Lai KC, Hu WH, Yuen ST, Leung SY, et al. Helicobacter pylori eradication to prevent gastric cancer in a high-risk region of China: a randomized controlled trial. JAMA 2004;291:187-194.

5. Takenaka R, Okada H, Kato J, Makidono C, Hori S, Kawahara Y, Miyoshi M, Yumoto E, Imagawa A, Toyokawa $\mathrm{T}$, et al. Helicobacter pylori eradication reduced the incidence of gastric cancer, especially of the intestinal type. Aliment Pharmacol Ther 2007;25:805-812.

6. Malfertheiner P, Megraud F, O'Morain C, Hungin AP, Jones R, Axon A, Graham DY, Tytgat G; European Helicobacter Pylori Study Group (EHPSG). Current concepts in the management of Helicobacter pylori infection--the Maastricht 2-2000 Consensus Report. Aliment Pharmacol Ther 2002;16:167-180.

7. Malfertheiner P, Megraud F, O’Morain C, Bazzoli F, ElOmar E, Graham D, Hunt R, Rokkas T, Vakil N, Kuipers EJ. Current concepts in the management of Helicobacter pylori infection: the Maastricht III Consensus Report. Gut 2007;56:772-781.

8. Lee JH, Cheon JH, Park MJ, Kim N, Lee DH, Kim JM, Kim JS, Jung HC, Song IS. The trend of eradication rates of second-line quadruple therapy containing metronidazole for Helicobacter pylori infection: an analysis of recent eight years. Korean J Gastroenterol 2005;46:94-98.

9. Houben MH, van de Beek D, Hensen EF, Craen AJ, Rauws EA, Tytgat GN. A systematic review of Helicobacter pylori eradication therapy--the impact of antimicrobial resistance on eradication rates. Aliment Pharmacol ther 1999; 13:1047-1055.

10. McLoughlin R, Racz I, Buckley M, O'Connor HJ, O'Morain C. Therapy of Helicobacter pylori. Helicobacter 2004;9:42-48.

11. Gisbert JP, Pajares JM. Review article: Helicobacter pylori "rescue" regimen when proton pump inhibitorbased triple therapies fail. Aliment Pharmacol Ther 2002;16:1047-1057.

12. Gaby AR. Helicobacter pylori eradication: are there alternatives to antibiotics? Altern Med Rev 2001;6:355-366.

13. Carson CF, Riley TV. Non-antibiotic therapies for infectious diseases. Commun Dis Intell 2003;27:S143-S146.

14. Lee SY, Shin YW, Hahm KB. Phytoceuticals: mighty but ignored weapons against Helicobacter pylori infection. J Dig Dis 2008;9:129-139.

15. Zojaji H, Talaie R, Mirsattari D, Haghazali M, Molaei M, Mohsenian N, Derakhshan F, Zali MR. The efficacy of Helicobacter pylori eradication regimen with and without vitamin C supplementation. Dig Liver Dis 2009;41:644647.

16. Park S, Yeo M, Jin JH, Lee KM, Jung JY, Choue R, Cho SW, Hahm KB. Rescue of Helicobacter pylori-induced cytotoxicity by red ginseng. Dig Dis Sci 2005;50:12181227.

17. Park S, Yeo M, Jin JH, Lee KM, Kim SS, Choi SY, Hahm KB. Inhibitory activities and attenuated expressions of 5-LOX with red ginseng in Helicobacter pylori-infected gastric epithelial cells. Dig Dis Sci 2007;52:973-982.

18. Kim DK, Lee JA, Kim YB, Lee KM, Hahm KB. A randomized controlled trial assessing Korean red ginseng treatment of Helicobacter pylori-associated chronic gastritis. Korean J Med 2007;72:20-28.

19. Lee JS, Kwon KA, Jung HS, Kim JH, Hahm KB. Korean 
red ginseng on Helicobacter pylori-induced halitosis: newer therapeutic strategy and a plausible mechanism. Digestion 2009;80:192-199.

20. Tangerman A. Halitosis in medicine: a review. Int Dent $\mathbf{J}$ 2002;52 Suppl 3:201-206.

21. Feller L, Blignaut E. Halitosis: a review. SADJ 2005;60:17-19.

22. Porter SR, Scully C. Oral malodour (halitosis). BMJ 2006;333:632-635.

23. Yoo SH, Jung HS, Sohn WS, Kim BH, Ku BH, Kim YS, Park SW, Hahm KB. Volatile sulfur compounds as a predictor for esophagogastroduodenal mucosal injury. Gut Liver 2008;2:113-118.

24. Leung WK, Lin SR, Ching JY, To KF, Ng EK, Chan FK, Lau JY, Sung JJ. Factors predicting progression of gastric intestinal metaplasia: results of a randomised trial on $\mathrm{He}$ licobacter pylori eradication. Gut 2004;53:1244-1249.

25. Sung JJ, Lin SR, Ching JY, Zhou LY, To KF, Wang RT, Leung WK, Ng EK, Lau JY, Lee YT, et al. Atrophy and intestinal metaplasia one year after cure of $H$. pylori infection: a prospective, randomized study. Gastroenterology 2000;119:7-14.

26. Kabir S. Effect of Helicobacter pylori eradication on incidence of gastric cancer in human and animal models: underlying biochemical and molecular events. Helicobacter 2009;14:159-171.

27. Pounder RE, Ng D. The prevalence of Helicobacter pylori infection in different countries. Aliment Pharmacol Ther 1995;9:33-39.

28. Kim JH, Kim HY, Kim NY, Kim SW, Kim JG, Kim JJ, Roe IH, Seo JK, Sim JG, Ahn H, et al. Seroepidemiological study of Helicobacter pylori infection in asymptomatic people in South Korea. J Gastroenterol Hepatol 2001;16:969-975.

29. Yim JY, Kim N, Choi SH, Kim YS, Cho KR, Kim SS, Seo GS, Kim HU, Baik GH, Sin CS, et al. Seroprevalence of Helicobacter pylori in South Korea. Helicobacter 2007;12:333-340.

30. Kamiji MM, de Oliveira RB. Non-antibiotic therapies for Helicobacter pylori infection. Eur J Gastroenterol Hepatol 2005; 17:973-981.

31. Zou J, Dong J, Yu XF. Meta-analysis: the effect of supplementation with lactoferrin on eradication rates and adverse events during Helicobacter pylori eradication therapy. Helicobacter 2009;14:119-127.

32. Cellini L, Di Campli E, Masulli M, Di Bartolomeo S, Allocati N. Inhibition of Helicobacter pylori by garlic extract (Allium sativum). FEMS Immunol Med Microbiol 1996;13:273-277.

33. Osato MS, Reddy SG, Graham DY. Osmotic effect of honey on growth and viability of Helicobacter pylori. Dig Dis Sci 1999;44:462-464.

34. Jones NL, Shabib S, Sherman PM. Capsaicin as an inhibitor of the growth of the gastric pathogen Helicobacter pylori. FEMS Microbiol Lett 1997;146:223-227.

35. Burger O, Ofek I, Tabak M, Weiss EI, Sharon N, Neeman I. A high molecular mass constituent of cranberry juice inhibits Helicobacter pylori adhesion to human gastric mucus. FEMS Immunol Med Microbiol 2000;29:295301.

36. Nir Y, Potasman I, Stermer E, Tabak M, Neeman I. Controlled trial of the effect of cinnamon extract on Helicobacter pylori. Helicobacter 2000;5:94-97.

37. Kim MN, Kim N, Lee SH, Park YS, Hwang JH, Kim JW, Jeong SH, Lee DH, Kim JS, Jung HC, et al. The effects of probiotics on PPI-triple therapy for Helicobacter pylori eradication. Helicobacter 2008;13:261-268.

38. Sachdeva A, Nagpal J. Meta-analysis: efficacy of bovine lactoferrin in Helicobacter pylori eradication. Aliment Pharmacol Ther 2009;29:720-730.

39. Sezikli M, Cetinkaya ZA, Sezikli H, Guzelbulut F, Tiftikçi A, Ince AT, Gokden Y, Yasar B, Atalay S, Kurdas OO. Oxidative stress in Helicobacter pylori infection: does supplementation with vitamins $\mathrm{C}$ and $\mathrm{E}$ increase the eradication rate? Helicobacter 2009; 14:280-285.

40. Chuang CH, Sheu BS, Huang AH, Yang HB, Wu JJ. Vitamin $\mathrm{C}$ and $\mathrm{E}$ supplements to lansoprazole-amoxicillinmetronidazole triple therapy may reduce the eradication rate of metronidazole-susceptible Helicobacter pylori infection. Helicobacter 2002;7:310-316.

41. Gotteland M, Brunser O, Cruchet S. Systematic review: are probiotics useful in controlling gastric colonization by Helicobacter pylori? Aliment Pharmacol Ther 2006;23:1077-1086.

42. Tiomny E, Arber N, Moshkowitz M, Peled Y, Gilat T. Halitosis and Helicobacter pylori. A possible link? J Clin Gastroenterol 1992;15:236-237.

43. Ierardi E, Amoruso A, La Notte T, Francavilla R, Castellaneta S, Marrazza E, Monno RA, Francavilla A. Halitosis and Helicobacter pylori: a possible relationship. Dig Dis Sci 1998;43:2733-2737.

44. Hoshi K, Yamano Y, Mitsunaga A, Shimizu S, Kagawa J, Ogiuchi H. Gastrointestinal diseases and halitosis: association of gastric Helicobacter pylori infection. Int Dent J 2002;52:207-211.

45. Katsinelos P, Tziomalos K, Chatzimavroudis G, Vasiliadis T, Katsinelos T, Pilpilidis I, Triantafillidis I, Paroutoglou G, Papaziogas B. Eradication therapy in Helicobacter pylori-positive patients with halitosis: long-term outcome. Med Princ Pract 2007;16:119-123. 
46. Lee H, Kho HS, Chung JW, Chung SC, Kim YK. Volatile sulfur compounds produced by Helicobacter pylori. J Clin Gastroenterol 2006;40:421-426.

47. Choi KS, Lee SJ, Lee JS, Hong KS, Kim JG, Kim YJ,
Hahm KB. Beneficial effect of Korean red ginseng on halitosis: attenuation of $\mathrm{H}_{2} \mathrm{~S}$ induced inflammatory mediators and cystathionine $\gamma$-lyase expression. J Ginseng Res 2009;33:367-377. 